\title{
miR-27b Suppresses Endothelial Cell Proliferation and Migration by Targeting Smad7 in Kawasaki Disease
}

\author{
Xing Rong ${ }^{a}$ Donghui Ge ${ }^{a}$ Danping Shen ${ }^{a} \quad X^{2}$ ianda Chen ${ }^{a} \quad$ Xuliang Wang ${ }^{a}$ \\ Lu Zhang $^{b}$ Chang Jia ${ }^{a}$ Jingjing Zeng ${ }^{a} Y_{\text {Yue'e He }}{ }^{a}$ Huixian Qiu ${ }^{a}$ \\ Xiaoping $\mathrm{Su}^{\mathrm{a}}$ Maoping $\mathrm{Chu}^{\mathrm{a}}$ \\ aChildren's Heart Center, the Second Affiliated Hospital and Yuying Children's Hospital, Institute of \\ Cardiovascular Development and Translational Medicine, Wenzhou Medical University, Wenzhou, ${ }^{\text {bThe }}$ \\ Second Clinical Medical College of Wenzhou Medical University, Wenzhou, China
}

\section{Key Words}

Kawasaki Disease $•$ miR-27b • Human Umbilical Vein Endothelial Cell • TGF- $\beta$ signaling pathway - Biomarker

\begin{abstract}
Background/Aims: Increasing evidence indicates that microRNAs (miRNAs) play important roles in Kawasaki disease (KD). Our previous study demonstrated that hsa-miR-27b-3p (miR$27 b$ ) was up-regulated in KD serum. However, the specific role of miR-27b in KD remains unclear. We aimed to investigate that miR-27b could be a biomarker and therapeutic target for $\mathrm{KD}$ treatment. As well, the specific mechanism of miR-27b effecting endothelial cell functions was studied. Methods: The expression of miR-27b and Smad7 was measured by qRT-PCR. Gain-of-function strategy was used to observe the effect of miR-27b on human umbilical vein endothelial cells (HUVECs) proliferation and migration. Bioinformatics analyses were applied to predict miR-27b targets and then we verified Smad7 by a luciferase reporter assay. Western blot was performed to detect the protein expression of Smad7, PCNA, MMP9, MMP12 and TGF- $\beta$-related genes. Results: We confirmed that miR-27b was shown to be dramatically up-regulated in KD serum and KD serum-treated HUVECs and that elevated expression of miR-27b suppressed the proliferation and migration of HUVECs. Furthermore, our results verified that miR-27b mediated cell functions by affecting the TGF- $\beta$ via targeting Smad7 in HUVECs. Conclusion: These results suggested that up-regulated miR-27b had a protective role in HUVECs proliferation and migration via targeting Smad7 and affecting TGF- $\beta$ pathway. Therefore, miR-27b represented a potential biomarker for KD and may serve as a promising therapeutic target for KD treatment.

Xing Rong and Donghui Ge contributed equally to this work.

Prof Maoping Chu

and Prof Xiaoping Su
Children's Heart Center, the Second Affiliated Hospital

Wenzhou Medical University, Wenzhou 325027, Zhejiang, (China)

Tel. 13506670567, E-Mail chmping@hotmail.com; bloooge@163.com 


\section{Cellular Physiology Cell Physiol Biochem 2018;48:1804-1814 \begin{tabular}{ll|l} 
and Biochemistry Published online: August 3, 2018 & $\begin{array}{l}\text { (c) } 2018 \text { The Author(s). Published by S. Karger AG, Basel } \\
\text { www.karger.com/cpb }\end{array}$
\end{tabular}

\section{Introduction}

Kawasaki disease (KD) is a multisystemic vasculitis syndrome most commonly affecting infants and young children. KD is the most common cause of coronary artery aneurysms (CAAs) in childhood. Moreover, 15 to $25 \%$ of untreated children develop CAAs or ectasia [1] and the risk is reduced only to 5\% after treatment with intravenous immunoglobin in acute KD [2, 3]. However, the mechanism of KD-induced vascular injury remains unclear and no specific biomarker is available. Chu et al. indicated that miR-223 might participate in vascular injury in KD [3]. Using a KD mouse model, interleukin (IL)-1 $\beta$ and caspase-1 were determined to be critical for Lactobacillus casei wall extract-mediated coronary arteritis. Additionally, these lesions can be prevented by IL-1Ra treatment [4]. In the absence of a diagnostic test and specific pathogenesis, clinicians must rely on the recognition of clinical signs that may not have manifested [5]. Therefore, there is an urgent need to identify a therapeutic target or biomarker for KD treatment.

MicroRNAs (miRNAs) are 20-26 nucleotides in length and are related to posttranscriptional repression of target mRNA gene expression. At present, numerous researches have concluded that miRNAs could be therapeutic target and be diagnostic biomarkers. In acute liver failure (ALF), miR-1224 may represent therapeutic target via inhibiting cell proliferation and promoting cell apoptotic [6]. In addition, using DNA-gold nanoparticle probes, miRNA could be better applied in clinical praxis as biomarkers [7]. One research group showed that miR-155-5p, miR-483-5p, and miR-451a may support the early diagnostic value of coronary plaque rupture [8]. In addition to the reports described above, extensive research has indicated that miRNAs play important roles in KD development. One study revealed that miR-145, whose targets included proteins involved in the transforming growth factor (TGF)- $\beta$ pathway, may play a crucial role in the vasculitis of KD [9]. However, the specific mechanism of miRNAs in KD remains unknown.

In the current report, we show that the expression of miR-27b was dramatically upregulated in KD serum and upregulation of miR-27b in HUVECs suppressed cell proliferation and migration by targeting Smad7 and regulating the TGF- $\beta /$ smad pathway. Therefore, we hypothesized that miR-27b may represent a latent biomarker in KD and serve as a therapeutic target for KD treatment.

\section{Materials and Methods}

\section{Study Subjects}

In present study, we included 34 acute KD children, 42 healthy children as controls, 15 febrile children and 18 convalescent KD children. All study subjects were recruited from the Second Affiliated Hospital and Yuying Children's Hospital of Wenzhou Medical University between March 2016 and May 2017. We have presented the clinical characteristics of research objects in Table 1. All patients diagnosed with KD had fever for at least five days and met at least four of five clinical criteria for KD (rash, conjunctival injection, cervical lymphadenopathy, oral mucosalchanges, and changes in the
Table 1. Characteristics of the clinical index independent validation cohort in different groups. WBC white blood cell, PLT platelet, ALT glutamic pyruvic transaminase, AST glutamic oxaloacetic transaminase, ESR erythrocyte sedimentation rate, NT-proBNP $\mathrm{N}$-terminal pro natriuretic peptide type $\mathrm{B}$

\begin{tabular}{lcccc}
\hline Groups & $\begin{array}{c}\text { Healthy } \\
\text { control }\end{array}$ & $\begin{array}{c}\text { Febrile } \\
\text { children }\end{array}$ & $\begin{array}{c}\text { Acute } \\
\text { KD }\end{array}$ & Convalescent KD \\
\hline Number & 42 & 15 & 34 & 18 \\
Male & $27(35.71)$ & $10(66.67)$ & $24(70.59)$ & $11(61.11)$ \\
Female & $15(64.29)$ & $5(33.33)$ & $10(29.41)$ & $7(38.89)$ \\
Age $($ months $)$ & $43.7 \pm 27.75$ & $49.27 \pm 32.78$ & $32.79 \pm 15.56$ & $30.68 \pm 27.18$ \\
WBC $\left(\times 10^{9} / \mathrm{L}\right)$ & $7.83 \pm 2.32$ & $12.17 \pm 6.04$ & $17.04 \pm 6.6$ & $8.23 \pm 2.82$ \\
PLT $\left(\times 10^{9}\right)$ & $326.29 \pm 72.66$ & $262.4 \pm 68.1$ & $396.75 \pm 88.98$ & $506.27 \pm 2.82$ \\
CRP & $/$ & $20.85 \pm 18.04$ & $76.36 \pm 63.24$ & $3.86 \pm 3.32$ \\
ALT & $17.12 \pm 11.15$ & $15.47 \pm 7.95$ & $77.73 \pm 114.1$ & $72.53 \pm 111.14$ \\
AST & $34.28 \pm 11.2$ & $33.4 \pm 11.74$ & $38.31 \pm 43.63$ & $42.71 \pm 18.92$ \\
NT-proBNP & $/$ & $/$ & $923.22 \pm 1399.5$ & $305.14 \pm 347.81$ \\
\hline
\end{tabular}




\section{Cellular Physiology Cell Physiol Biochem 2018;48:1804-1814 \begin{tabular}{l|l} 
and Biochemistry Published 10.1159/000492354 3,2018 & $\begin{array}{l}\text { (c) } 2018 \text { The Author(s). Published by S. Karger AG, Basel } \\
\text { www.karger.com/cpb }\end{array}$ \\
\hline
\end{tabular} \\ Rong et al.: miR-27b in Kawasaki Disease}

extremities) or three of five criteria and coronary artery abnormalities documented by echocardiogram. The patients with acute KD were not treated with globulin, while inflammatory indices of convalescent patients returned to normal and clinical symptoms disappeared. Febrile children were with respiratory tract infections. All patients gave signed, informed consent for the serum to be used for scientific research. Ethical approval for the study was obtained from the Second Affiliated Hospital and Yuying Children's Hospital of Wenzhou Medical University.
Table 2. A list of the primers in the PCR. Abbreviations: F, forward primer; R, reverse primer; RT, Reverse Transcription, WT, wild type; MUT, mutant

\begin{tabular}{lc}
\hline Name & Primer Sequence \\
\hline miRNA R & 5'-GTGCAGGGTCCGAGGT -3' \\
U6 RT & 5'- AACGCTTCACGAATT -3' \\
U6 F & 5'- CTCGCTTCGGCAGCA -3' \\
miR-27b RT & 5'-GTCGTATCCAGTGCAGGGTCCGAGGTATTCGCACTGGATACGACGCAGAA -3' \\
miR-27b F & 5'-GCCGCTTCACAGTGGCTAAG -3' \\
cel-miR-39 RT & 5'-GTCGTATCCAGTGCAGGGTCCGATTGATTCGCACTGGATACGACCAAGCT -3' \\
cel-miR-39 F & 5'-GCCGCTCACCGGGTGTAAATC -3' \\
has-Smad7 F & 5'-GCTGTGTTGCTGTGAATCT -3' \\
has-Smad7 R & 5'- CGGGTATCTGGAGTAAGGA - 3' \\
has-GAPDH F & 5'- AACTCTGGTAAAGTGGATATTG -3' \\
has-GAPDH R & 5'-GGTGGAATCATATTGGAACA -3' \\
Smad7 (WT) F & 5'-AAACTAGTGTGTTCAGGTGGCCGGATC -3' \\
Smad7 (WT) R & 5'-GGAAGCTTTTCACAGCAACACAGCCTCTTG -3' \\
Smad7 (MUT) F & 5'-AAACTAGTGTGTTCAGGTGGCCGGATC -3' \\
Smad7 (MUT) R & 5'-GGAAGCTTTAGTGTGCAACACAGCCTCTTG -3' \\
\hline
\end{tabular}

\section{Cell line and cell transfection}

The Human umbilical vein endothelial cells (HUVECs) were purchased from ATCC and were cultured in RPMI 1640 containing 10\% foetal bovine serum (FBS) and 1\% penicillin- streptomycin. Cells were maintained at $37{ }^{\circ} \mathrm{C}$ in a humidified atmosphere with $5 \%$ CO2. To detect the miR-27b expression in cells, HUVECs were incubated with $20 \%$ healthy control or acute KD serum. After 48 hours, cells were collected. Before cells were incubated, serum was heat-inactivated in $56^{\circ} \mathrm{C}$ for $30 \mathrm{~min}$ and filtered by filter tip. Transfection with miR-27b mimics (ribobio, Guangzhou) and siRNA (ribobio, Guangzhou) were performed using Lipofectamine 2000 (Invitrogen, USA).

\section{RNA isolation and $q R T-P C R$}

Total RNA was extracted from acute KD, healthy controls, febrile children and convalescent KD serum using Trizol LS (Sigma, USA) and from HUVECs using Trizol (Sigma, USA) according to the manufacturer's instructions. RNAs were reverse transcripted using ReverTra Ace qPCR RT Kit (Toyobo, Japan). Detection of miR-27b and Smad family member 7 (Smad7) expression were performed by qRT-PCR. As an internal control of cells, U6 was used for miRNA template normalization and GAPDH was used for other template. For serum samples, Caenorhabditis elegans miR-39 (Cel-miR-39) was added as a spike-in control. All experiments were done in triplicate. The primers were listed in Table 2.

\section{Luciferase reporter assay}

Luciferase reporter vector was constructed by cloning human Smad7 mRNA sequence into pMIRReport construct (Ambion, Austin, USA). Smad7 mRNA fragment (from 771 to 830), which was located in CDS of Smad7, was amplified and cloned into the luciferase repoter via SpeI and HindIII sites. Briefly, cells plated in a 48-well plate were co-transfected with $50 \mathrm{nM}$ miRNA mimics or negative control oligonucleotides (NC), $50 \mathrm{ng}$ of firefly luciferase reporter and $10 \mathrm{ng}$ of pRL-TK (Promega, USA) using the JetPRIME reagent (Polyplus-transfection) [10]. Cells were collected 36 hours after transfection and analyzed using DualLuciferase Reporter Assay System (Promega, USA). All the primers were listed in Table 2.

\section{Cell proliferation assay}

Cell viability was quantified by measuring the reduction of MTS to formazan product using CellTiter $96{ }^{\circledR} \mathrm{AQ}_{\text {ueous }}$ One Solution Cell Proliferation Assay (Promega; Madison, WI) according to the manufacturer's protocol. The optical density at $492 \mathrm{~nm}$ was determined with the microplate reader (Molecular Devices; Sunnyvale, CA). 


\section{Cell migration assay}

The migration ability of HUVECs was first determined by using wound healing. Each well of a six-well plate was seeded with $5 \times 10^{5}$ cells and cultured for $24 \mathrm{~h}$ to $100 \%$ confluence. The cells were scratched with the head of a 200- $\mu$ lip and then cultured for $48 \mathrm{~h}$. these cells in each group were then photographed for analysis.

The second method to test migration ability of HUVECs was transwell chambers method. Chambers have upper and lower culture compartments that are separated by polycarbonate membranes with 8 - $\mu \mathrm{m}$ pores (Costar, Cambridge, MA, USA). Transfected cells in serum-free medium were seeded at $5 \times 10^{4}$ in the top chamber and the bottom chamber was filled with RPMI-1640 medium containing 20\% FBS as a chemoattractant. The chamber was incubated at $37^{\circ} \mathrm{C}$ in a humidified incubator containing $5 \% \mathrm{CO}_{2}$. Eight hours later, cells that migrated to the underside of the membrane were fixed with $4 \%$ paraformaldehyde (Sigma Aldrich, St. Louis, MO), stained with crystal violet (Beyotime, Shanghai, China), imaged, and counted with a microscope (Leica, UK). All experiments were performed in triplicate.

\section{Western blotting}

Total proteins were obtained by a RIPA lysis buffer containing protease and phosphatase inhibitors. Protein samples were loading in 10\% SDS-PAGE gel and transferred to polyvinylidene fluoride (PVDF) membranes. The membrane was blocked with 5\% non-fat milk and then was incubated with primary antibodies including Smad7 (CY2385, Abways Technology ), Smad2/3 (\#8685, Cell signaling), p-Smad2/3 (\#8828, Cell signaling), E-cadherin (\#3195, Cell signaling), N-cadherin (\#13116, Cell signaling), Vimentin (\#12826, Cell signaling), PCNA (\#13110, Cell signaling), MMP9 (\#13667, Cell signaling) and MMP12 (ab137444, Abcam) at $4{ }^{\circ} \mathrm{C}$ overnight. Membranes were washed three times with TBS plus $0.1 \%$ Tween 20 and next incubated with a goat and mouse anti-rabbit secondary antibody (Pierce, IL, USA). The proteins were detected using ECL reagents. All experiments were performed in triplicate.

\section{Statistical analysis}

All data are presented as means \pm standard deviation (s. d.) from at least three independent experiments. Student's test was used to analyze the difference between two experimental groups and a two-tailed $P<0.05$ was taken to indicate statistical significance.

\section{Results}

miR-27b is increased in KD serum and miR-27b levels in serum can distinguish patients with $K D$

We previously revealed that many miRNAs, including miR-27b, are differentially expressed in serum from KD patients compared with healthy children [3]. However, the functions of these miRNAs in KD are not clear. To further verify upregulation of miR-27b in $\mathrm{KD}$, serum from acute KD patients and healthy controls, as well as febrile and convalescent KD patients were used to analyze. We found that miR-27b expression was much higher in serum from acute KD patients than healthy controls, as well as febrile and convalescent KD patients (Fig. 1A). Together, these data showed that miR-27b was remarkably up-regulated in KD serum. However, whether miR-27b could be a biomarker to distinguish patients with KD remains unknown.

Nextly, we used receiver operating characteristic (ROC) curves to assess the diagnostic value of miR-27b for KD. As shown in Fig. 1B, ROC curve analysis showed a sensitivity of $85.3 \%$ and a specificity of $100 \%$ at the threshold, representing the largest diagnosis efficiency for discriminating children with acute KD from healthy controls, while the miR-27b cutoff $\Delta$ Ct value was 3.16, with an area under the curve (AUC) of $0.953(\mathrm{p}<0.001,95 \%$ confidence interval [CI] 0.899-1.000). As shown in Fig. 1C, miR-27b had a sensitivity of $67.6 \%$ and a specificity of $93.3 \%$ for discriminating children with acute KD from febrile children, while the miR-27b cutoff $\Delta$ Ct value was 4.12 , with an AUC of 0.873 ( $p<0.001,95 \%$ CI $0.774-$ 0.971). As shown in Fig. 1D, miR-27b had a sensitivity of $91.4 \%$ and a specificity of $66.7 \%$ for discriminating children with acute KD from convalescent children, while the miR-27b 
cutoff $\Delta$ Ct value was 2 , with an AUC of 0.824 ( $p<0.001,95 \%$ CI $0.702-$ $0.946)$. Collectively, these results suggest that serum miR-27b could serve as a biomarker for KD diagnosis.

Upregulation of miR-27b inhibits the proliferation and migration of HUVECS

Many studies showed that the increase of miRNA expression in the blood can cause the increase of expression in the endothelial cells and thus affect the function of endothelial cells $[3,11]$. In order to investigate whether KD serum can increase the expression of miR$27 \mathrm{~b}$ in endothelial cells and the function of upregulation of miR$27 \mathrm{~b}$ in KD serum, we performed the following experiments. Firstly, HUVECs were incubated with acute KD and healthy control serum. Dramatically, miR-27b was increased in $\mathrm{KD}$ serum-treated HUVECs (Fig. 2A). Nextly, miR$27 \mathrm{~b}$ mimics were also transiently transfected into HUVECs, our results showed that $\mathrm{miR}-27 \mathrm{~b}$

Fig. 2. Upregulation of miR-27b inhibits the proliferation and migration of HUVECs. (A) miR-27b was examined in HUVECs treated with $20 \%$ normal or KD serum. The expression of miR-27b was examined by qRT-PCR and the miR-27b expression level was normalized to U6 RNA expression for the subsequent analysis. (B) miR-27b mimics were transfected into HUVECs and the miR-27b level was determined by qRT-PCR. (C) HUVEC proliferation was determined by MTS after transfection with the miR-27b mimics or a negative control (NC). (D-G) The migration ability of HUVECs was evaluated in vitro using wound healing (D, E) and Transwell chamber (F, G) assays after transfection with the NC or miR-27b mimics. All experiments were done in triplicate. Data were subjected to Student's t-test. ${ }^{*}$ p $<0.05,{ }^{* *} \mathrm{p}<0.01$, and ${ }^{* * *} \mathrm{p}<0.001$ compared to the control.

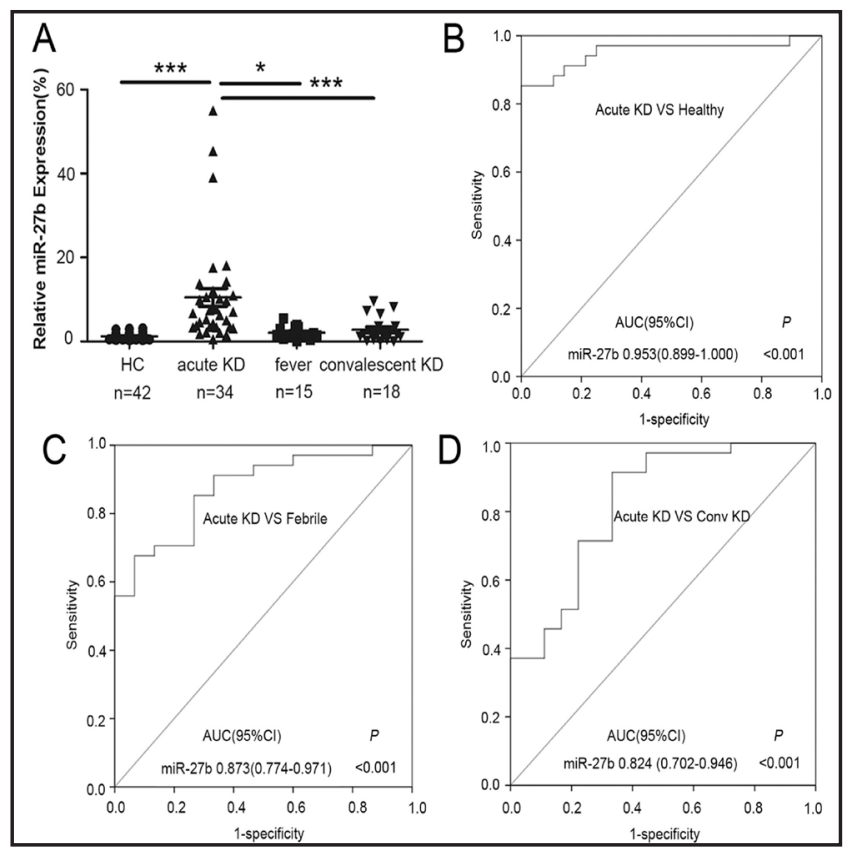

Fig. 1. miR-27b is increased in KD serum and miR-27b levels in serum can distinguish patients with KD. (A) Serum miR$27 \mathrm{~b}$ was examined in healthy controls ( $\mathrm{HC}, \mathrm{n}=42$ ), acute KD patients $(n=34)$, febrile children $(n=15)$, and convalescent KD patients $(n=18)$ using qRT-PCR. (B) The ROC curve analysis of miR-27b levels for discriminating patients with acute KD from healthy control. (C) The ROC curve analysis of miR-27b levels for discriminating patients with acute KD from febrile children. (D) The ROC curve analysis of miR-27b levels for discriminating patients with acute KD from convalescent children.

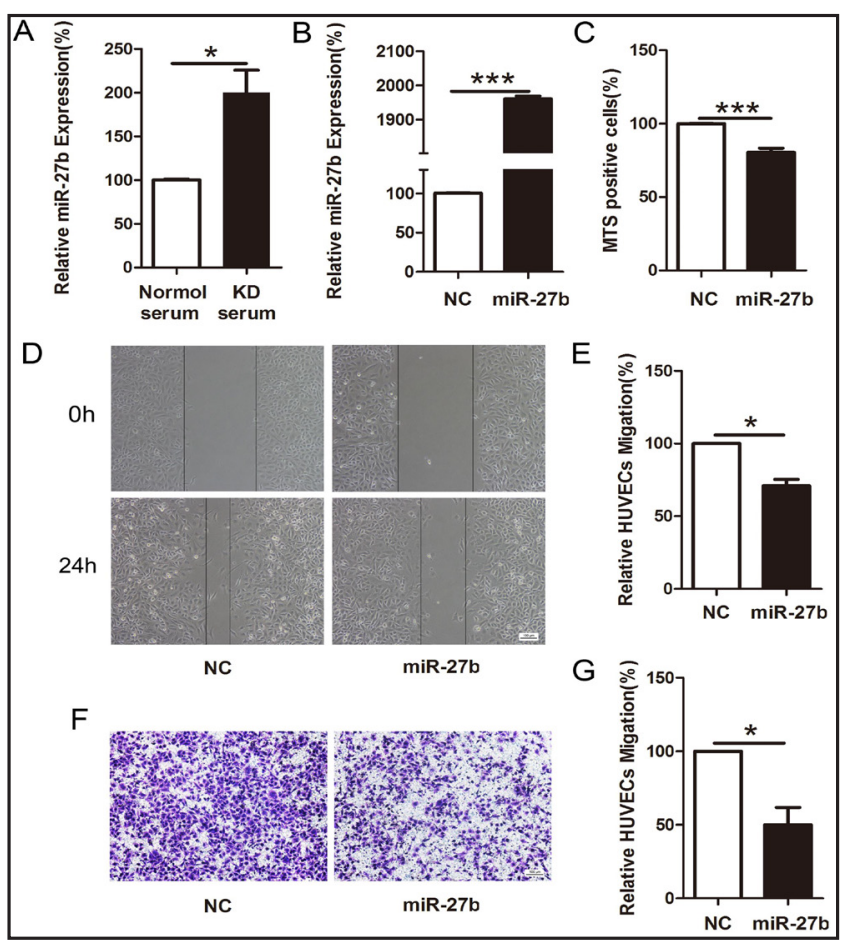


was significantly increased in HUVECs transfected with miR-27b mimics (Fig. 2B). Finally, the function of upregulation of miR-27b in HUVECs were performed. A cell proliferation assay (MTS assay) showed that the upregulation of miR-27b in HUVECs significantly inhibited cellular proliferation (Fig. 2C). In addition, the overexpression of miR-27b resulted in decreased cellular migration according to wound healing (50 \pm 11.85 vs. $100 \pm 0.03333$, p < 0.05; Fig. $2 \mathrm{D}, \mathrm{E})$ and Transwell chamber $(70.93 \pm 4.404$ vs. $100 \pm 0.05, p$ $<0.05$; Fig. 2F, G) assays. Conclusively, these results proved that KD serum increased miR-27b in HUVECs and upregulation of miR-27b in HUVECs inhibited cell proliferation and migration.

\section{miR-27b targets and upregulates Smad7 protein in HUVECS}

We then aimed to investigate the mechanism of the upregulation of miR-27b. DIANA-TarBase includes over half a million experimentally confirmed miRNA-mRNA interactions [12]. Therefore, we used DIANA-TarBase (http://diana.imis. athena-innovation.gr/) to identify target genes of miR-27b. Many miR-27b target genes from DIANA-TarBase are related to the TGF- $\beta$ signaling pathway, which is associated with cell proliferation and migration [13]. TGF- $\beta$ signaling pathway-related miR-27b target genes are listed in Table 3. We focused on Smad7, a negative regulator of the TGF- $\beta$ signaling pathway [14]. To determine whether Smad7 is a genuine target of miR-27b, we first performed luciferase reporter assays in HUVECs. As shown in Fig. 3A and B, cells transfected with miR-27b exhibited a dramatic increase in luciferase activity. Next, we investigated whether endogenous Smad7 in HUVECs was regulated Table 3. TGF- $\beta$ signaling pathway related target genes

\begin{tabular}{ll}
\hline Gene Name & Gene Ensemble id \\
\hline FST & ENSG00000134363 \\
TGFBR1 & ENSG00000106799 \\
ID2 & ENSG00000115738 \\
SMAD9 & ENSG00000120693 \\
THBS1 & ENSG00000137801 \\
CUL1 & ENSG00000055130 \\
ID4 & ENSG00000172201 \\
BMP8B & ENSG00000116985 \\
ACVR1 & ENSG00000115170 \\
ACVR2B & ENSG00000114739 \\
PPP2R1A & ENSG00000105568 \\
SMURF1 & ENSG00000198742 \\
ZFYVE9 & ENSG00000157077 \\
MAPK3 & ENSG00000102882 \\
SP1 & ENSG00000185591 \\
ACVR1C & ENSG00000123612 \\
BAMBI & ENSG00000095739 \\
LTBP1 & ENSG00000049323 \\
ID3 & ENSG00000117318 \\
SMAD7 & ENSG00000101665 \\
MAPK1 & ENSG00000100030 \\
PPP2R1B & ENSG00000137713 \\
TGFBR2 & ENSG00000163513 \\
BMPR2 & ENSG00000204217 \\
\hline & \\
\hline
\end{tabular}
in a similar manner. HUVECs were transfected with miR$27 \mathrm{~b}$ mimics or negative control oligonucleotides, and Smad7 mRNA and protein levels were examined by qRT-PCR and western blotting, respectively. The level of Smad7 mRNA and protein were consistently and substantially up-regulated by miR-27b (Fig. 3C, D). In summary, these results clarify that miR-27b directly targets Smad7 in HUVECs.

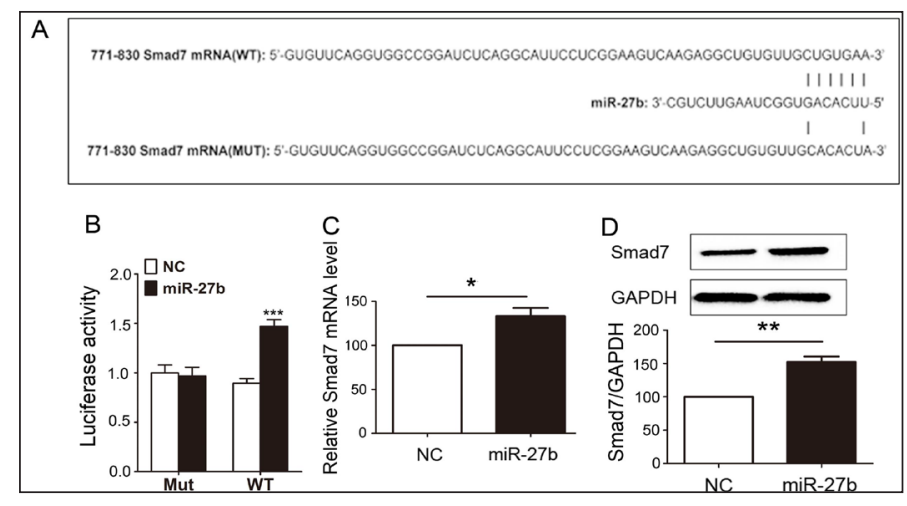

Fig. 3. miR-27b targets and upregulates Smad7 protein in HUVECs (A) Wild-type (WT) and mutant (Mut) of putative miR-27b targeting sequences in Smad7 mRNA. (B) Analysis of luciferase activity in HUVECs. The normalized luciferase activity of negative control oligonucleotides was set as relative luciferase activity. (C, D) Representative qRT-PCR and Western blots showed Smad7 mRNA and protein levels in miR-27b mimic- and NC mimic-transfected HUVECs. All experiments were done in triplicate. Data were subjected to Student's t-test. ${ }^{*} \mathrm{p}<0.05,{ }^{* *} \mathrm{p}<0.01$, and ${ }^{* * *} \mathrm{p}<0.001$. 


\section{Cellular Physiology Cell Physiol Biochem 2018;48:1804-1814 \begin{tabular}{ll|l} 
and Biochemistry Published online: August 3, 2018 & $\begin{array}{l}\text { (C) } 2018 \text { The Author(s). Published by S. Karger AG, Basel } \\
\text { www.karger.com/cpb }\end{array}$
\end{tabular}

\section{Upregulation of $\operatorname{miR}-27 \mathrm{~b}$ in HUVECS suppresses TGF- $\beta$ signaling pathway and EndoMT process \\ Several studies have} demonstrated that the TGF- $\beta$ signaling pathway enhances cell proliferation and migration by regulating the endothelialmesenchymal transition (EndoMT) in endothelial cells [9, 15]. Our results demonstrated that miR-27b targets and upregulates the expression of Smad7, a negative feedback loop of the TGF- $\beta$ signaling pathway. Therefore, we hypothesized that miR-27b may regulate TGF- $\beta$ pathway and EndoMT process. In order to investigate this hypothesis, we performed the following experiments. Our results showed that the phosphorylation of Smad2/3 ( $\mathrm{p}$-Smad2/3), a gene involved in the TGF- $\beta$ pathway, was decreased in cells transfected with the miR-27b mimics. In addition, the expression of vascular endothelial cadherin (E-cadherin), an endothelialspecific marker, was increased in miR-27b mimic-transfected cells. Conversely, the expression of mesenchymal markers, including vimentin and $\mathrm{N}$-cadherin, were decreased (Fig. 4). Taken together, these data indicate that upregulation of miR-27b in HUVECs suppresses TGF- $\beta$ signaling pathway and EndoMT process.

\section{Restrained Smad7 rescues miR-27b-induced HUVEC functions and the signaling pathway \\ We determined that the} overexpression of miR-27b suppresses the proliferation and migration of HUVECs. We also found that miR-27b up-regulates the Smad7 protein in HUVECs and suppresses TGF- $\beta$ signaling pathway and EndoMT process. Therefore, we hypothesized that miR-27b regulates cell proliferation and migration by targeting Smad7 in HUVECs. In order to investigate this

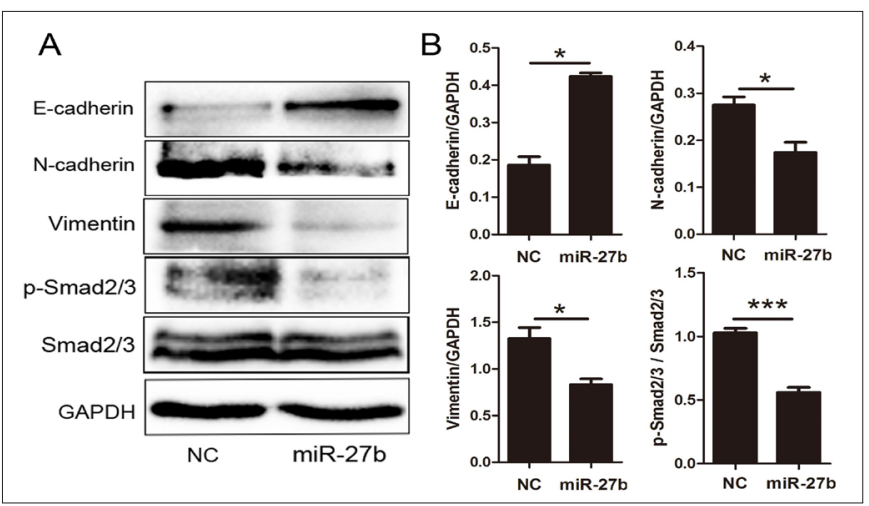

Fig. 4. Upregulation of miR-27b in HUVECs suppresses TGF- $\beta$ signaling pathway and EndoMT process (A) Western blots analysis of the expression of TGF- $\beta /$ smad signaling pathway and EndoMT related marker, including p-Smad2/3, E-cadherin, $\mathrm{N}$-cadherin, Vimentin in different groups (NC, miR-27b). (B) The quantitative analysis of the proteins. NC, Negative control. All experiments were done in triplicate. Data were subjected to Student's t-test. ${ }^{*} \mathrm{p}<0.05,{ }^{* * *} \mathrm{p}<0.001$.

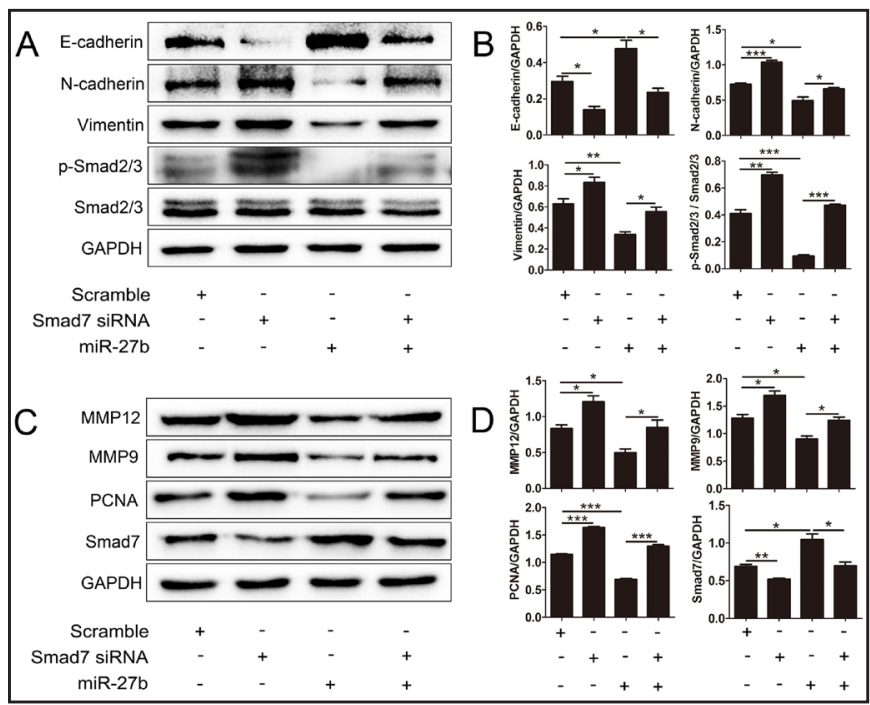

Fig. 5. Restrained Smad7 rescues miR-27b-induced HUVEC TGF- $\beta$ pathway and functions related proteins. HUVECs were transfected with miR-27b and/or infected with Smad7 siRNA. (A)The TGF- $\beta$ pathway related proteins levels were determined by Western blot analysis at $48 \mathrm{~h}$ culture of different groups (Scramble, miR$27 \mathrm{~b}$, miR-27b+ Smad7 siRNA). (B) The quantitative analysis of the proteins. (C) The cell function related proteins levels were determined by Western blot analysis at $48 \mathrm{~h}$ culture of different groups. (D) The quantitative analysis of the proteins. All experiments were done in triplicate. Data were subjected to Student's t-test. ${ }^{*} \mathrm{p}<0.05,{ }^{* *} \mathrm{p}<0.01$, and ${ }^{* * *} \mathrm{p}<0.001$. 


\section{Cellular Physiology Cell Physiol Biochem 2018;48:1804-1814 and Biochemistry Published online: August 3, $2018 \quad \begin{aligned} & \text { DOI } 2018 \text { The Author(s). Published by S. Karger AG, Basel } \\ & \text { www.karger.com/cpb }\end{aligned}$ \\ Rong et al.: miR-27b in Kawasaki Disease}

hypothesis, the following experiments rescue studies were performed in HUVECs. Smad7 siRNA inhibited the expression of Smad7 protein, when compared with the scramble group (Fig. 5C and D). The expression of N-cadherin, Vimentin, p-Smad2/3 protein increased and the expression of E-cadherin protein was inhibited after transfected Smad7 siRNA when compared with the scramble group (Fig. $5 \mathrm{~A}$ and $\mathrm{B}$ ). In addition, Smad7 siRNA can also reverse the inhibitory effect of miR-27b on the expression of TGF- $\beta$ pathway related proteins. Moreover, the expression of proliferation and migration related proteins, including proliferating cell nuclear antigen (PCNA), matrix metallopeptidase 9 (MMP9), matrix metallopeptidase 12 (MMP12) increased after transfected Smad7 siRNA when compared with the scramble group (Fig. 5C and D). In addition, Smad7 siRNA can also reverse the inhibitory effect of miR-27b on the expression of cell function related proteins. Nextly, cell functions were performed. MTS assay showed that Smad7 siRNA could promote cellular proliferation when compared with the scramble group (Fig. 6A). In addition, Smad7 siRNA can also reverse the inhibitory effect of miR-27b on cellular proliferation. The wound healing (Fig. 6B and C) and Transwell assays (Fig. 6D and E) showed that Smad7 siRNA could promote cellular migration when compared with the scramble group. In addition, Smad7 siRNA can also reverse the inhibitory effect of miR-27b on cellular migration. Taken together, these results demonstrate that miR$27 \mathrm{~b}$ regulates HUVEC proliferation and migration by targeting Smad7.

\section{Discussion}

The main finding of this study is that upregulation of miR-27b in KD serum could serve as a biomarker for KD. In addition, overexpression of miR-27b in HUVECs inhibits cell proliferation and migration, and the underlying mechanism likely involves the promotion of Smad7 and feedback repression of the TGF- $\beta$ pathway, resulting in suppression of the EndoMT process. This study provides evidence that miR-27b could represent an

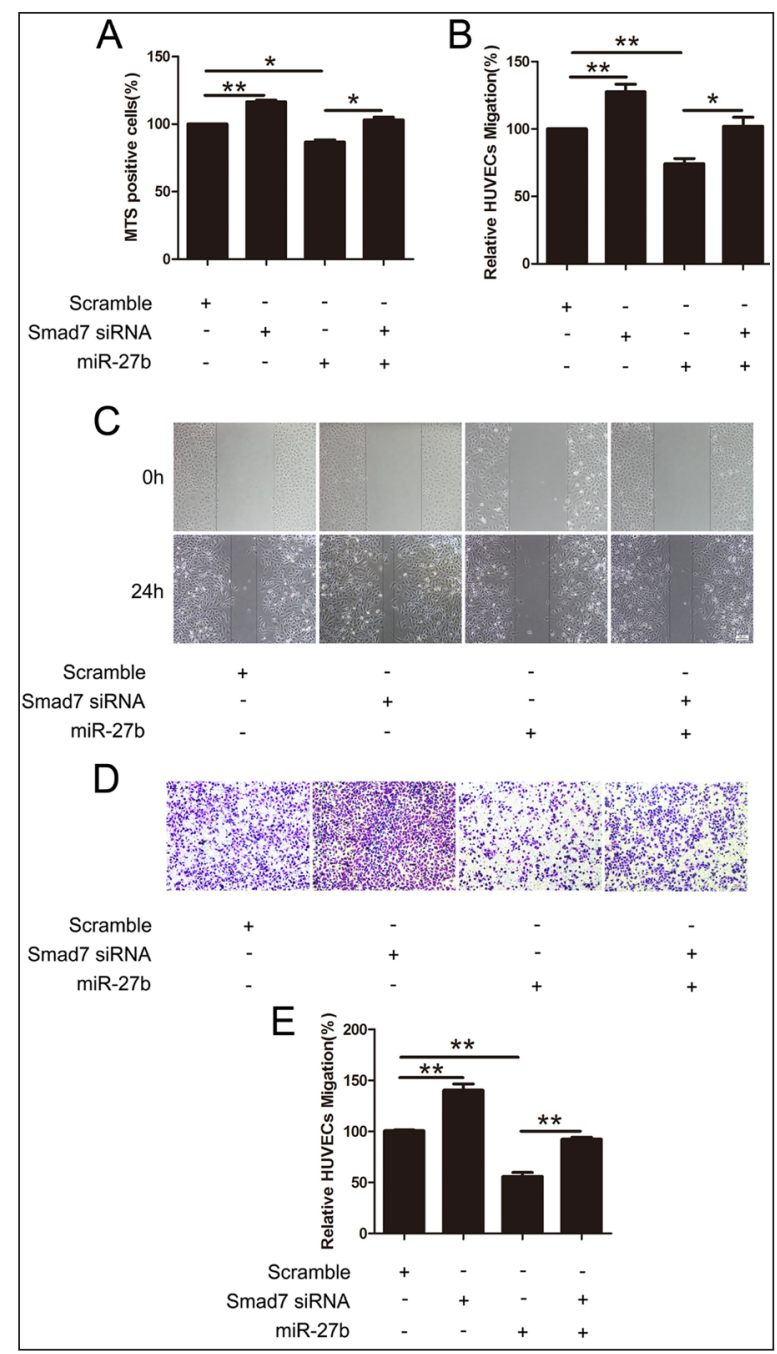

Fig. 6. Restrained Smad7 rescues miR-27b-induced HUVEC functions.HUVECs were transfected with miR-27b and/or infected with Smad7 siRNA. (A) Cell proliferation was determined by MTS after $48 \mathrm{~h}$ culture of different groups (Scramble, miR-27b, miR-27b+ Smad7 siRNA). (B) The quantitative analysis of the relative migrated percentage of HUVECs using wound healing in different groups. (C) Representative images of wound healing assay of HUVECs after $48 \mathrm{~h}$ culture of different groups. (D) Representative images of transwell migrated assay of HUVECs which were cultured in the chambers with different groups for $8 \mathrm{~h}$ and (E) The quantitative analysis of the relative migrated percentage of HUVECs using Transwell chamber assays in different groups. All experiments were done in triplicate. Data were subjected to Student's t-test. ${ }^{*} \mathrm{p}<0.05$, $^{* *} \mathrm{p}<0.01$. 
original biomarker and therapeutic target for KD.

Interestingly, miR-27b is expressed in endothelial cells [16]. Many researchers have verified that miR-27b plays an important role in endothelial cells. Biyashev et al. demonstrated that miR-27b plays a crucial role in promoting endothelial tip cell fate via its targets in zebrafish [17]. Urbich et al. reported a dramatic promotion of endothelial cell sprouting via semaphorin $6 \mathrm{~A}$ in vitro and in vivo [18]. Furthermore, Boon et al. verified that miR-27b enhances angiogenesis and plays a part in the atheroprotective mechanism [19]. In the current study, our results found that miR-27b, which was firstly reported targeting Smad7, inhibited cell proliferation and migration by targeting Smad7 in HUVECs. Interestingly, our results revealed that miR-27b up-regulated the Smad7 expression in HUVECs, which was similar to many previous studies. For example, one study reported that miR-369-3, Let-7, and the synthetic miRNA miRcxcr4 up-regulated the translation of target mRNAs by binding to AU-rich elements (AREs), which is transformed into a translation activation signal [20]. In another study, a similar mechanism was reported in which miR-466l combines with the IL-10 3'-untranslated region AREs to prevent IL-10 mRNA degradation [21]. Furthermore, miR-373 induces E-cadherin expression by targeting its promoter [22].

$\mathrm{KD}$ is an important immune illness resulting in multisystem vasculitis in childhood. At present, clinical doctors diagnose KD only on the basis of clinical symptoms due to the lack of a specific biomarker or laboratory test. A previous study showed that interferon-gammainducible protein 10 (IP-10), a chemokine secreted by several cells, was highly increased in acute KD, which is useful for its diagnosis [23]. Aberrant miR-155/SOCS-1 signaling and the overexpression of miR-31 may be involved in the function of regulatory $\mathrm{T}$ cells, which are associated with the development of KD [24]. Another study revealed that serum miR-200c and miR-371-5p were overexpressed in KD patients [25]. In our study, serum validation and ROC curve analysis were performed and revealed that miR-27b was highly up-regulated in acute KD serum and was highly specific and sensitive for the diagnosis of KD.

Vascular injury is the most common and serious complication of KD. Wang et al. reported that serum Th1 and Th2 cytokine expression were higher in KD patients with coronary artery lesions (CALs) than those without CALs [26]. Breunis et al. hypothesized that genetic variation may be involved in the development of CALs [27]. Another study revealed that peripheral blood mononuclear cell miR-93 may regulate the expression of vascular endothelial growth factor $A$ and is involved in the pathogenesis of arteritis in acute KD [28]. Recently, one research showed that, the mechanism of miRNA-involved blood vessel damage, particularly the protective mechanism, remains unclear. One research showed that KD-induced endothelial cell apoptotic could be inhibited by knockdown of miR-223, which was up-regulated in KD serum [3]. In addition, Another study showed that miR-125a$5 p$ increased in plasma induced endothelial cell apoptotic [29]. Our results revealed that upregulation of miR-27b inhibits endothelial cell proliferation and migration by increasing Smad7 expression. This may be the first protective mechanism of up-regulated miRNA in KD vasculitis.

The TGF- $\beta$ pathway is important in many diseases, including KD. Shimizu et al. demonstrated that genetic variation in TGF- $\beta$ pathway genes affects the susceptibility to KD and CAA formation [30]. Another study revealed that products of TGF- $\beta$ pathway-related genes expressed in cells in the injured coronary arterial wall from KD autopsies [15]. EndoMT is defined as a phenotypic change of normal endothelial cells to mesenchymal cells and enhances cell proliferation and migration. Moreover, TGF- $\beta$ plays a central role in actuating EndoMT progression [31,32]. A few studies have focused on the relationship between the EndoMT and KD. He et al. proved that KD sera induced endothelial cells undergoing the EndoMT [33]. In our study, we assumed that miR-27b inhibits the TGF- $\beta$ pathway to influence the cellular EndoMT by targeting Smad7 to protect vascular endothelial cells. Altogether, we demonstrated high expression of miR-27b in KD serum. We conclude that miR-27b could serve as a new biomarker for KD diagnosis and may exert a protective function by inhibiting the EndoMT in HUVECs by targeting Smad7.

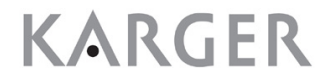




\section{Cellular Physiology Cell Physiol Biochem 2018;48:1804-1814

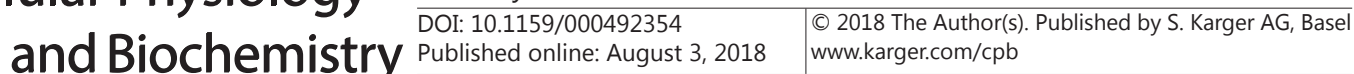

Rong et al.: miR-27b in Kawasaki Disease

\section{Acknowledgements}

Thanks Shanghai Zeheng biotech co, LTD for Luciferase reporter assay detection. This work was funded by the Natural Science Foundation of China (81770502, 31470849), the Zhejiang Provincial Natural Science Foundation (LQ16H020008, LQ16H020006), Zhejiang medical and health science and technology program (2017KY475).

\section{Disclosure Statement}

All authors declare no conflict of interests.

\section{References}

1 Abou Sherif S, Ozden Tok O, Taskoylu O, Goktekin O, Kilic ID: Coronary artery aneurysms: A review of the epidemiology, pathophysiology, diagnosis, and treatment. Frontiers in cardiovascular medicine 2017;4:24.

2 Newburger JW, Takahashi M, Gerber MA, Gewitz MH, Tani LY, Burns JC, Shulman ST, Bolger AF, Ferrieri P, Baltimore RS, Wilson WR, Baddour LM, Levison ME, Pallasch TJ, Falace DA, Taubert KA, Committee on Rheumatic Fever E, Kawasaki D, Council on Cardiovascular Disease in the Y, American Heart A, American Academy of P: Diagnosis, treatment, and long-term management of kawasaki disease: A statement for health professionals from the committee on rheumatic fever, endocarditis and kawasaki disease, council on cardiovascular disease in the young, american heart association. Circulation 2004;110:2747-2771.

3 Chu M, Wu R, Qin S, Hua W, Shan Z, Rong X, Zeng J, Hong L, Sun Y, Liu Y, Li W, Wang S, Zhang C: Bone marrowderived microrna-223 works as an endocrine genetic signal in vascular endothelial cells and participates in vascular injury from kawasaki disease. Journal of the American Heart Association 2017;6

-4 Lee Y, Schulte DJ, Shimada K, Chen S, Crother TR, Chiba N, Fishbein MC, Lehman TJ, Arditi M: Interleukin1 beta is crucial for the induction of coronary artery inflammation in a mouse model of kawasaki disease. Circulation 2012;125:1542-1550.

5 Burns JC: The riddle of kawasaki disease. The New England journal of medicine 2007;356:659-661.

6 Roy S, Bantel H, Wandrer F, Schneider AT, Gautheron J, Vucur M, Tacke F, Trautwein C, Luedde T, Roderburg C: Mir-1224 inhibits cell proliferation in acute liver failure by targeting the antiapoptotic gene nfib. Journal of hepatology 2017

7 Degliangeli F, Kshirsagar P, Brunetti V, Pompa PP, Fiammengo R: Absolute and direct microrna quantification using DNA-gold nanoparticle probes. Journal of the American Chemical Society 2014;136:2264-2267.

$>8$ Li S, Lee C, Song J, Lu C, Liu J, Cui Y, Liang H, Cao C, Zhang F, Chen H: Circulating micrornas as potential biomarkers for coronary plaque rupture. Oncotarget 2017;8:48145-48156.

-9 Xiang Y, Zhang Y, Tang Y, Li Q: Malat1 modulates tgf-beta1-induced endothelial-to-mesenchymal transition through downregulation of mir-145. Cellular physiology and biochemistry : international journal of experimental cellular physiology, biochemistry, and pharmacology 2017;42:357-372.

10 Li Y-F, Li S-H, Liu Y, Luo Y-T: Long noncoding rna cir promotes chondrocyte extracellular matrix degradation in osteoarthritis by acting as a sponge for mir-27b. Cellular Physiology and Biochemistry 2017;43:602-610.

11 Liu Y, Luo F, Wang B, Li H, Xu Y, Liu X, Shi L, Lu X, Xu W, Lu L, Qin Y, Xiang Q Liu Q: Stat3-regulated exosomal mir-21 promotes angiogenesis and is involved in neoplastic processes of transformed human bronchial epithelial cells. Cancer letters 2016;370:125-135.

12 Vlachos IS, Paraskevopoulou MD, Karagkouni D, Georgakilas G, Vergoulis T, Kanellos I, Anastasopoulos IL, Maniou S, Karathanou K, Kalfakakou D, Fevgas A, Dalamagas T, Hatzigeorgiou AG: Diana-tarbase v7.0: Indexing more than half a million experimentally supported mirna:Mrna interactions. Nucleic acids research 2015;43:D153-159.

13 Wang Z, Han Z, Tao J, Wang J, Liu X, Zhou W, Xu Z, Zhao C, Wang Z, Tan R, Gu M: Role of endothelial-tomesenchymal transition induced by tgf-beta1 in transplant kidney interstitial fibrosis. Journal of cellular and molecular medicine 2017 


\section{Cellular Physiology Cell Physiol Biochem 2018;48:1804-1814 \begin{tabular}{l|l|l} 
DOI: 10.1159/000492354 & and Biochemistry Published online: August 3, 2018 & $\begin{array}{l}\text { O } 2018 \text { The Author(s). Published by S. Karger AG, Basel } \\
\text { www.karger.com/cpb }\end{array}$ \\
\cline { 2 - 3 }
\end{tabular}}

Rong et al.: miR-27b in Kawasaki Disease

14 Nakao A, Afrakhte M, Moren A, Nakayama T, Christian JL, Heuchel R, Itoh S, Kawabata M, Heldin NE, Heldin $\mathrm{CH}$, ten Dijke P: Identification of smad7, a tgfbeta-inducible antagonist of tgf-beta signalling. Nature 1997;389:631-635.

15 Shimizu C, Oharaseki T, Takahashi K, Kottek A, Franco A, Burns JC: The role of tgf-beta and myofibroblasts in the arteritis of kawasaki disease. Human pathology 2013;44:189-198.

16 Kuehbacher A, Urbich C, Zeiher AM, Dimmeler S: Role of dicer and drosha for endothelial microrna expression and angiogenesis. Circulation research 2007;101:59-68.

17 Biyashev D, Veliceasa D, Topczewski J, Topczewska JM, Mizgirev I, Vinokour E, Reddi AL, Licht JD, Revskoy SY, Volpert OV: Mir-27b controls venous specification and tip cell fate. Blood 2012;119:2679-2687.

-18 Urbich C, Kaluza D, Fromel T, Knau A, Bennewitz K, Boon RA, Bonauer A, Doebele C, Boeckel JN, Hergenreider E, Zeiher AM, Kroll J, Fleming I, Dimmeler S: Microrna-27a/b controls endothelial cell repulsion and angiogenesis by targeting semaphorin 6a. Blood 2012;119:1607-1616.

19 Boon RA, Hergenreider E, Dimmeler S: Atheroprotective mechanisms of shear stress-regulated micrornas. Thrombosis and haemostasis 2012;108:616-620.

20 Vasudevan S, Tong Y, Steitz JA: Switching from repression to activation: Micrornas can up-regulate translation. Science 2007;318:1931-1934.

-21 Ma F, Liu X, Li D, Wang P, Li N, Lu L, Cao X: Microrna-466l upregulates il-10 expression in tlr-triggered macrophages by antagonizing rna-binding protein tristetraprolin-mediated il-10 mrna degradation. Journal of immunology 2010;184:6053-6059.

-22 Place RF, Li LC, Pookot D, Noonan EJ, Dahiya R: Microrna-373 induces expression of genes with complementary promoter sequences. Proceedings of the National Academy of Sciences of the United States of America 2008;105:1608-1613.

23 Ko TM, Kuo HC, Chang JS, Chen SP, Liu YM, Chen HW, Tsai FJ, Lee YC, Chen CH, Wu JY, Chen YT: Cxcl10/ip-10 is a biomarker and mediator for kawasaki disease. Circulation research 2015;116:876-883.

-24 Zhao XD, Zhang W, Liang HJ, Ji WY: Overexpression of mir -155 promotes proliferation and invasion of human laryngeal squamous cell carcinoma via targeting socs1 and stat3. PloS one 2013;8:e56395.

-25 Yun KW, Lee JY, Yun SW, Lim IS, Choi ES: Elevated serum level of microrna (mirna)-200c and mirna-371-5p in children with kawasaki disease. Pediatric cardiology 2014;35:745-752.

26 Wang Y, Wang W, Gong F, Fu S, Zhang Q, Hu J, Qi Y, Xie C, Zhang Y: Evaluation of intravenous immunoglobulin resistance and coronary artery lesions in relation to th1/th2 cytokine profiles in patients with kawasaki disease. Arthritis and rheumatism 2013;65:805-814.

-27 Breunis WB, Davila S, Shimizu C, Oharaseki T, Takahashi K, van Houdt M, Khor CC, Wright VJ, Levin M, Burns JC, Burgner D, Hibberd ML, Kuijpers TW, International Kawasaki Disease Genetics C: Disruption of vascular homeostasis in patients with kawasaki disease: Involvement of vascular endothelial growth factor and angiopoietins. Arthritis and rheumatism 2012;64:306-315.

28 Saito K, Nakaoka H, Takasaki I, Hirono K, Yamamoto S, Kinoshita K, Miyao N, Ibuki K, Ozawa S, Watanabe K, Bowles NE, Ichida F: Microrna-93 may control vascular endothelial growth factor a in circulating peripheral blood mononuclear cells in acute kawasaki disease. Pediatric research 2016;80:425-432.

29 Li Z, Jiang J, Tian L, Li X, Chen J, Li S, Li C, Yang Z: A plasma mir-125a-5p as a novel biomarker for kawasaki disease and induces apoptosis in huvecs. PloS one 2017;12:e0175407.

-30 Shimizu C, Jain S, Davila S, Hibberd ML, Lin KO, Molkara D, Frazer JR, Sun S, Baker AL, Newburger JW, Rowley AH, Shulman ST, Burgner D, Breunis WB, Kuijpers TW, Wright VJ, Levin M, Eleftherohorinou H, Coin L, Popper SJ, Relman DA, Fury W, Lin C, Mellis S, Tremoulet AH, Burns JC: Transforming growth factor-beta signaling pathway in patients with kawasaki disease. Circulation Cardiovascular genetics 2011;4:16-25.

-31 van Meeteren LA, ten Dijke P: Regulation of endothelial cell plasticity by tgf-beta. Cell and tissue research 2012;347:177-186.

-32 Medici D, Shore EM, Lounev VY, Kaplan FS, Kalluri R, Olsen BR: Conversion of vascular endothelial cells into multipotent stem-like cells. Nature medicine 2010;16:1400-1406.

-33 He M, Chen Z, Martin M, Zhang J, Sangwung P, Woo B, Tremoulet AH, Shimizu C, Jain MK, Burns JC, Shyy JY: Mir-483 targeting of ctgf suppresses endothelial-to-mesenchymal transition: Therapeutic implications in kawasaki disease. Circulation research 2017;120:354-365. 